\title{
Self-Medication of Senegalese Women through Social Networks
}

\author{
Niang Khadim ${ }^{1,2}$, Jean A. D. Tine2, Mboup Fatima Zahra², Bassoum Omar², \\ Fatoumata B. Diongue', Amadou I. Diallo², Faye Adama ${ }^{2}$ \\ ${ }^{1}$ Public Health Department, Gaston Berger University (UGB) of Saint-Louis, Senegal \\ ${ }^{2}$ Institut de Santé et Développement, Cheikh Anta Diop University, Dakar, Senegal \\ Email:khadimniang@outlook.com
}

How to cite this paper: Khadim, N. Tine, J.A.D., Zahra, M.F., Omar, B., Diongue, F.B., Diallo, A.I. and Adama, F. (2020) Self-Medication of Senegalese Women through Social Networks. Health, 12, 396-406. https://doi.org/10.4236/health.2020.124032

Received: January 2, 2020

Accepted: April 24, 2020

Published: April 27, 2020

Copyright (อ 2020 by author(s) and Scientific Research Publishing Inc. This work is licensed under the Creative Commons Attribution-NonCommercial International License (CC BY-NC 4.0). http://creativecommons.org/licenses/by-nc/4.0/ (c) (i) \&) Open Access

\begin{abstract}
Self-medication is a form of self-care which has evolved considerably with the development of digital technology. It particularly challenges public health actors given the risks to which it may be exposed if it is not properly supervised. The aim of this work was to study the knowledge, attitudes and practices of Senegalese women on self-medication through social networks. A transversal descriptive study was conducted from June 10 to 30, 2019. It concerned all Senegalese women registered in at least one of the following women's Facebook groups: Femme chic, Femme leader, Ladies club or Entre yaays. A study information sheet was posted on the wall of these different groups, and enabled consenting women to find a questionnaire deployed online directly through a link. Consenting women were able to complete the data collection tool directly online. The proportions were compared by setting the alpha risk at $5 \%$. A total of 508 women were surveyed. The results thus showed a high prevalence $(68.9 \%)$ of self-medication. A proportion of $46.3 \%$ of those self-medicated used Facebook or the Internet as a source of information to find the drugs to use. The advice received from these groups related to hygiene and dietary measures (96.1\%), consultation with health personnel (54.6\%), consultation with a traditional healer $(50.4 \%)$ and taking medication $(41.8 \%)$. The health problems most treated with these self-medications were headaches $((84.6 \%)$ and painful periods $(45.1 \%)$. Simple analgesics $(84.6 \%)$ and vitamins $(66.9 \%)$ were the most recommended drugs, but it was also found antibiotics $(40.0 \%)$, centrally acting analgesics (20.0\%), anti-diabetics (6.9\%) and antihypertensive (5.4\%). Oral tablets (92.3\%) remained the most widely used dosage forms, but eye drops (5.4\%) and injectables (5.4\%) were also found. Although searching for information on Facebook/internet, women obtained the drugs from pharmacies $(72.4 \%)$ or the family medicine box (19\%). Regarding self-medication on Facebook, its easy accessibility (67.8\%)
\end{abstract}


was the main motivation for which women chose it, as well as saving time (33.9\%). Advice on health through the Facebook network is important for Senegalese women but taking medication on advice from these forums remains low. A better presence for health actors in social networks is becoming urgent in order to promote responsible self-medication.

\section{Keywords}

Automedication, Women's Health, Internet, Social Networks, Senegal

\section{Introduction}

Self-medication with drugs or alternative medicines is a common form of care that calls upon public health actors [1]. The World Health Organization (WHO) has indicated that self-medication can be acceptable, when properly taught and controlled until it fully integrates into society behavior. However, it can be a threat to public health if it is not supervised [2].

In Africa, several studies have presented prevalence of self-medication. Among students residing at the Kasapa Campus of the University of Lubumbashi, A prevalence of $99 \%$ has been found [3]. In Ghana, a study that looked specifically at self-medication with antibiotics found a prevalence of 70\% [4].

In Senegal, this practice is also very common and has been the subject of several studies [5] [6] [7] [8] [9] which revealed very alarming prevalence. We can take as examples. A study entitled "Self-treatment of fever in the Dakar district" revealed a prevalence of $81 \%$ [5]. Another study carried out in Grand-Yoff had shown that $80 \%$ of those surveyed practiced self-medication [10].

Although self-care does not constitute recent behavior and has been the subject of several works, current practices as the representations which underlie them have new characteristics, in connection with the technology revolution information and communication (ICT). A significant number of individuals choose a therapeutic product by engaging with their group, whose experience they harness. Up to global knowledge accessible by internet [11], this is what explains the success of medical websites, which are not lacking in sociability, and is expressed particularly in forums which host exchanges of very personal experiences putting people in touch with communities of virtual patients [11]. However, this aspect of self-medication remains poorly documented, hence the purpose of this work to determine its extent.

\section{Methodology}

\subsection{Study Framework}

Senegal is situated in the western-most part of the African continent on the Atlantic Ocean where Europe. Africa and the Americas converge and at the crossroads of major air and shipping routes. 
According to the Senegalese population projection report 2013-2063 [12], the population of Senegal is estimated in 2019 at 16,209,125 inhabitants, $50.2 \%$ of whom are women.

Senegal has a satisfactory level of telephone and internet coverage, and the low literacy rate $(57.9 \%)$ is not a constraint to the mobile penetration rate estimated at $103.2 \%$ in March 2017 . The mobile telephony market is still dominated by prepaid offers (99.4\% of the total population). The penetration rate of internet services was 57.6\% in June 2017 with 8,965,507 internet subscribers [13].

Analysis of the digital sector indicates that telecommunications infrastructure remains among the most developed and efficient in West Africa thanks to significant investments made in terms of capacity and modernization. Indeed. on the infrastructure sub-index. the "Network Readiness Index" (NRI) from World Economic Forum 2016 placed Senegal in the leading group in West Africa with Nigeria. Côte d'Ivoire and Ghana and in the $14^{\text {th }}$ place in Africa [13].

Compared to media and the internet in particular, the 2017 Demographic and Health Survey [14] found that $29 \%$ of women and $43 \%$ of men reported using the internet in the past 12 months.

\subsection{Study Type}

This is a cross-sectional survey with descriptive aims on knowledge. attitudes and practices in terms of self-medication on the Facebook network among Senegalese women which took place from June 10 to 30. 2019.

\subsection{Study Population and Sampling Protocol}

The study population was represented by all of the women registered in one or more of the following four Facebook groups:

- "Femme chic": created on June 12. 2016. with 145.000 members;

- “Ladies club": created on April 16. 2016. with 56.300 members;

- "Femme leader": created on April 6. 2015. with 43.700 members;

- “Entre yaays": created on March 25. 2013 with 11.700 members.

To be included in this study, the woman had to declare to be of Senegalese nationality and to be registered on one of the targeted Facebook groups. Since participation in the study was done on a voluntary basis, the only criterion for non-inclusion online was that the questionnaire was not completed.

The sample size was calculated by the Schwartz formula $\left(n=\left(\varepsilon^{2} \times p \times q\right) / i^{2}\right)$.

With prevalence of self-medication in women by Facebook's groups not known, we chose $50 \%, \varepsilon=1.96$ and an accuracy of $5 \%$, the number is equal to 385 individuals.

No survey was conducted, all members wishing to participate in the study during the collection period were included.

\subsection{Collection of Data}

A questionnaire following the specific objectives of the study and drawing inspi- 
ration from studies on the same theme. It included 45 questions divided into three sections:

- Socio-professional data: age, marital status, number of children, schooling, type of schooling, level of schooling, current school situation, income-generating activity, status of nursing staff, etc.

- Use of social networks: number of social networks subscribed, date of subscription on Facebook, number of friends on Facebook, frequency of connection on Facebook, number of groups of women on Facebook, etc.

- Knowledge and practices of self-medication: knowledge of self-medication, practice of self-medication, health problems causing self-medication, search for medical information through social network.

The questionnaire was scanned in XLSform format with the application Open Data Kit (ODK). After validation of the format, its online deployment was made thanks to the Ona.IO platform.

From the Ona.IO platform, a link was generated and then posted on the wall of the different Facebook groups targeted by the study. Information of these groups was therefore posted on their walls and an information form posted which made it possible to share the objectives and the ethical considerations of the study. At the bottom of this form was the link to the questionnaire.

This link enabled the various consenting members to fill out the online questionnaire directly, without the possibility of participating repeatedly through the same IP address.

The questionnaire was therefore self-administered over a three-week period from June 10 to 30.2019 , time to reach the sample size.

\subsection{Data Analysis}

At the end of the data collection, a database in csv format was generated from the online platform. This database was cleaned and then analyzed with the $\mathrm{R}$ software.

The description of the qualitative variables was done through frequency measurements, that of the quantitative variables called for the calculation of arithmetic means with their standard deviation.

\subsection{Ethical Considerations}

The consent of the people surveyed was previously obtained through the information form. Consent was given by the opening of the questionnaire and its filling which was done remotely on a voluntary basis.

Respondents were informed of the objectives and constraints of the study, of their rights to refuse to participate in the study or to leave it at any time. Anonymity and confidentiality were respected.

\section{Results}

After three weeks of posting the questionnaire, 508 women were surveyed in the 
targeted Facebook groups.

The women surveyed were on average 30.7 years old, with a standard deviation of 8.7 years. The extreme ages were 58 and 15, with a predominance of women 40 to 45 (Figure 1).

Study participants subscribed on average to 3 social networks, with a standard deviation of 1.2 social networks. After Facebook. the women surveyed mainly subscribed to WhatsApp and Twitter (Figure 2).

The women surveyed were educated (98.8\%), married (45.5\%) and had an income-generating activity (54.1\%). They lived in the Dakar region (49.8\%) and had been active on Facebook for five years and more in $49.8 \%$ (Table 1).

The women interviewed addressed health issues in the Facebook groups of which they were a member in $62.2 \%$ of the cases. The sources of information used by women in the event of a health problem were mainly health professionals (77\%), the Internet (59\%) and social networks (18\%) including Facebook

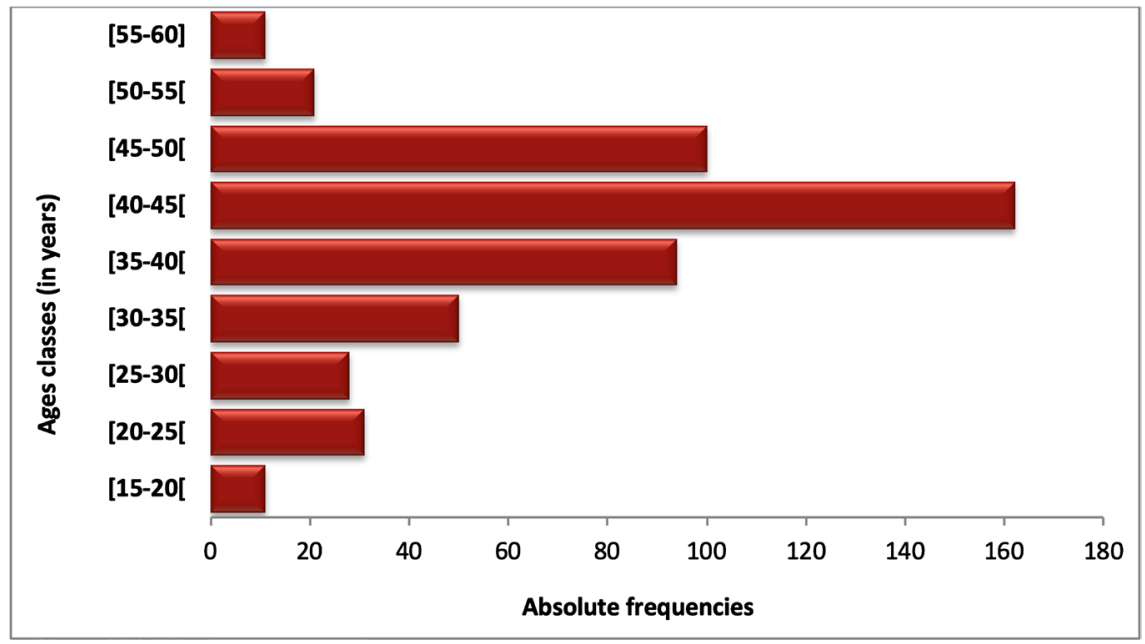

Figure 1. Distribution of women surveyed by age group $(n=508)$.

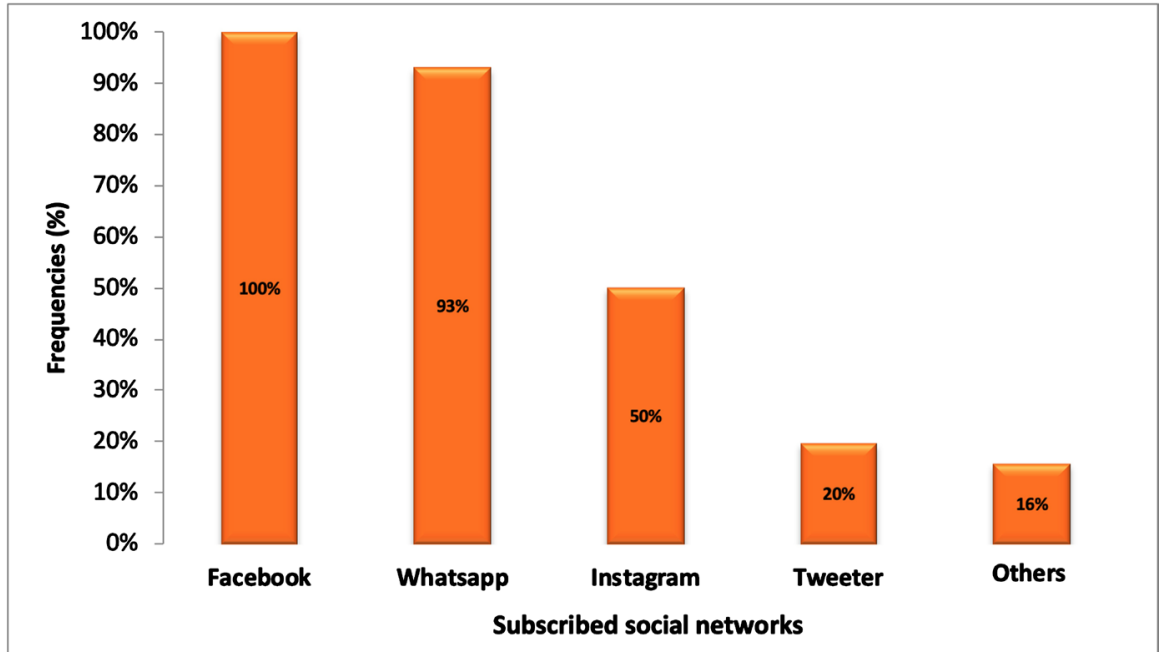

Figure 2. Distribution of women surveyed according to social networks subscribed ( $\mathrm{n}=$ 508). 
Table 1. Characteristics of women $(n=508)$.

\begin{tabular}{|c|c|c|}
\hline Parameters & Absolute frequencies (n) & Relative frequencies (\%) \\
\hline \multicolumn{3}{|l|}{ Level of education } \\
\hline Higher & 371 & 73.0 \\
\hline Secondary & 102 & 20.1 \\
\hline Primary & 29 & 5.7 \\
\hline Not in school & 6 & 1.2 \\
\hline \multicolumn{3}{|l|}{ Marital status } \\
\hline Married & 231 & 45.5 \\
\hline Single & 219 & 43.1 \\
\hline Divorced & 45 & 8.8 \\
\hline Widow & 13 & 2.6 \\
\hline \multicolumn{3}{|c|}{ Income-generating activity (IGA) } \\
\hline No IGA & 233 & 45.9 \\
\hline Possession of IGA & 275 & 54.1 \\
\hline \multicolumn{3}{|l|}{ Residence } \\
\hline Dakar & 253 & 49.8 \\
\hline Other regions of Senegal & 198 & 39.0 \\
\hline Diaspora & 57 & 11.2 \\
\hline \multicolumn{3}{|l|}{ Seniority in Facebook } \\
\hline Less than 5 years & 255 & 50.2 \\
\hline 5 years and over & 253 & 49.8 \\
\hline \multicolumn{3}{|c|}{ Number of friends on Facebook } \\
\hline ]0 - 100 friends] & 24 & 4.7 \\
\hline ] 100 - 500 friends] & 121 & 23.8 \\
\hline Over 500 friends & 363 & 71.5 \\
\hline \multicolumn{3}{|l|}{ Frequency of Facebook use } \\
\hline Continuously & 117 & 23.0 \\
\hline Several times a day & 246 & 48.4 \\
\hline Less than once a day & 145 & 28.5 \\
\hline
\end{tabular}

\section{(15\%) (Figure 3).}

Self-medication was practiced by $68.9 \%$ of the women surveyed. Headache and dysmenorrhea (painful menstruation) were the most treated problems by self-medication among the women surveyed (Table 2).

Among the respondents 311 had once seen on a wall, or received medical information through Facebook, a proportion of $61.2 \%$. In this proportion, $41.8 \%$, or 130 were related to drug prescriptions. The other advice related to hygienic dietetics $(96.1 \%)$, a consultation with a qualified health professional (54.6\%), a consultation with a healer (50.4\%). 


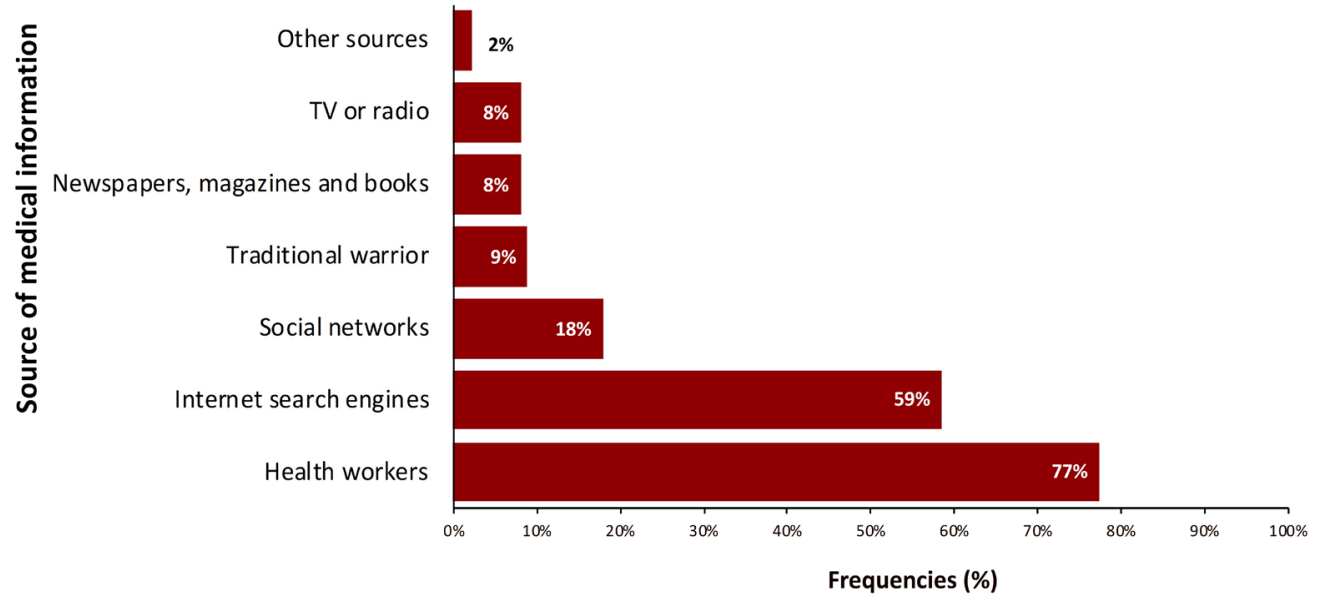

Figure 3. Distribution of women surveyed by medical information sources $(n=508)$.

Table 2. Health problems managed by self-medication $(n=350)$.

\begin{tabular}{ccc}
\hline $\begin{array}{c}\text { Top } 10 \text { health problems treated } \\
\text { by self-medication }\end{array}$ & $\begin{array}{c}\text { Absolute frequencies } \\
(\mathrm{n})\end{array}$ & $\begin{array}{c}\text { Relative frequencies } \\
(\%)\end{array}$ \\
\hline Headaches & 296 & 84.6 \\
Painful menstruation & 158 & 45.1 \\
Belly aches & 143 & 40.9 \\
Diarrhea & 126 & 36.0 \\
Tiredness & 124 & 35.4 \\
Cough & 119 & 34.0 \\
Angina & 117 & 33.4 \\
Toothaches & 98 & 28.0 \\
Fever & 97 & 27.7 \\
Constipation & 94 & 26.9 \\
\hline
\end{tabular}

A proportion of $16 \%$ of women receiving advice on taking medication through Facebook systematically checked them with a health professional. The most commonly used drugs were simple painkillers (paracetamol) and vitamins. However, other very sensitive products were also recommended through Facebook such as central action painkillers (20.0\%), antibiotics (40.0\%), antihypertensive drugs (5.4\%) and antidiabetics (6.9\%) (Table 3).

The oral tablet (92.3\%) and syrup (50.0\%) were the most common dosage forms found in self-medication on Facebook. Injectables and eye drops were found in $5.4 \%$ of cases, however (Table 3 ).

Among women who received medication advice through Facebook, 60\%, or 78 , had used it. The drugs were mainly purchased from pharmacies (72.4\%). No woman reported buying it on the street (Table 4).

The use of Facebook groups to self-medicate would be advantageous compared to medical consultations because of its accessibility, time savings and the 
Table 3. Drugs recommended on Facebook groups used $(n=130)$.

\begin{tabular}{|c|c|c|}
\hline Parameters & Absolute frequencies ( $n$ ) & Relative frequencies (\%) \\
\hline \multicolumn{3}{|l|}{ Top 10 drugs recommended } \\
\hline Painkillers with simple action & 110 & 84.6 \\
\hline Vitamins & 87 & 66.9 \\
\hline Appetite stimulants & 59 & 45.4 \\
\hline Antibiotics & 52 & 40.0 \\
\hline Deparasitant & 50 & 38.5 \\
\hline Gynecological drugs & 37 & 28.5 \\
\hline Laxatives & 35 & 26.9 \\
\hline Dermal creams & 34 & 26.2 \\
\hline Dietary products & 32 & 24.6 \\
\hline Central action painkillers & 26 & 20.0 \\
\hline Gastric bandages & 25 & 19.2 \\
\hline \multicolumn{3}{|c|}{ Galenic forms of recommended products across } \\
\hline Oral tablet & 120 & 92.3 \\
\hline Syrup/concentrate & 65 & 50.0 \\
\hline Ointment & 56 & 43.1 \\
\hline Dermal cream & 45 & 34.6 \\
\hline Drinkable ampoule & 28 & 21.5 \\
\hline Ova gynecological & 23 & 17.7 \\
\hline Suppository & 15 & 11.5 \\
\hline Eye drops & 7 & 5.4 \\
\hline Injectable & 7 & 5.4 \\
\hline
\end{tabular}

Table 4. Medication recommended on the Facebook groups used $(n=78)$.

\begin{tabular}{ccc}
\hline Parameters & Absolute frequencies (n) & Relative frequencies (\%) \\
\hline Origin of self-medication drugs & 56 & 72.4 \\
Pharmacies & 15 & 19.0 \\
Medicine cabinet (home) & 8 & 10.3 \\
Bio store & 7 & 8.6 \\
Traditional medicine practitioners & 5 & 6.9 \\
Online purchase & 5 & 6.9 \\
Offered by an acquaintance & 0 & 0.0 \\
Street & & \\
Benefits of self-medication on Facebook & 53 & 67.8 \\
Accessibility & 26 & 33.3 \\
Saving time & 22 & 28.8 \\
The effectiveness of the advice provided & 15 & 18.6 \\
Savings on consultation fees & 11 & 13.6 \\
Others & &
\end{tabular}


effectiveness of the advice provided (Table 4).

\section{Discussion}

This study focused on Senegalese women subscribing to female Facebook groups (Femme chic, Ladies club, Entre Yaays, or Femme leaders). The main limitation of this study is the fact that the data collected was exclusively declarative. No verification could be made. However, this approach gives an advantage because it makes the respondent more comfortable. The ethical considerations on anonymity and data security being shared in the information form, and the absence of collection of personal data was an advantage because the woman was alone and free to give all the answers, thus avoiding bias courtesy.

In our study, the average age of the participants is 30.7 years. This can be justified by the chosen study framework, the Facebook social network, used mainly by young internet users. The results of a Senmarkting study converge with this, revealing that in Senegal, users between 16 and 25 years of age dominate social networks like Facebook and Instagram [15]. The women who participated in our study were educated in $98.8 \%$ of cases. And $97.6 \%$ of them had gone to French school to a higher level (73\%). These results are also justified by the study framework which is more used by educated people. And they agree with those from the 2017 DHS showing that internet use increases with educational level, passing among women from $7 \%$ among those with no education to $63 \%$ among those with intermediate / secondary level or more [14].

The study reveals that among the 508 women surveyed 350 self-medication, a prevalence of $68.9 \%$. This prevalence is below those found by other studies carried out in Senegal. Thiam T [9] found an 80\% prevalence in Grand Yoff ; Samb ES had objectified during a survey in the Kaolack region a prevalence of $83 \%$ [16]. In the African region higher prevalence have been found. Chiribagula VB [3] had found in students aged 18 to 35 living on the Kasapa campus of the University of Lubumbashi a prevalence of 99\%, Kitengye LJ [17], meanwhile ended up with $57.4 \%$ self-medication in the elderly. However, none of these studies evaluated self-medication specifically through social networks, it was evaluated across all communication channels.

The main health problems that lead women to self-medicate in general were mainly headaches, painful periods and stomach aches. This is due to the frequency of these symptoms in women and their impression of "not serious". According to Hariri J [18] the indications for self-medication are mainly asthenia, fever, digestive and intestinal pain, rhinitis, and minor dermatological conditions. He justifies this by a clear view of the signs but also the obtaining of drugs without medical prescription. According to Chiribagula VB [3] malaria (82.4\%), fever (65.5\%), headache (65.5\%), cough (62\%) as well as bacterial infections (50.6\%) are the top five causes of self-medication. Samb ES [16] highlighted three self-medicating symptoms, namely headache (91\%), fever (68\%), cough (65\%), and diarrhea (64\%). 
Regarding the most used drugs we found painkillers with simple action (84.6\%), vitamins (66.9\%), appetite stimulants (45.4\%) and antibiotics (40\%). This could be due on the one hand to the over-the-counter sale of these drugs (without prescription) but also to a cost less (Bamako Initiative), but above all the fact that these drugs are very well known to the general public. Queneau [19] found overlapping results with as main self-prescriptions aspirin and other analgesics (30.6\%), ointments (8.9\%), hypnotics and tranquilizers (8.6\%), laxatives (6.1\%), gastric dressings (3.7\%) and tonics (2.7\%).

The dosage forms of the drugs used were mainly oral tablets (92.3\%), syrup / concentrate (50\%), ointments (43.1\%) dermal creams (34.6\%), and ova gynecological (17.7\%), Chiribagula VB found that the tablet (37\%) was the most used form of self-medication [17].

The reasons cited as leading to self-medication on Facebook or the internet are, the accessibility of Facebook (67.8\%), the saving of time (33.9\%), and money (18.6\%) on consultation, reliability of medical information previously received (28.8\%). Samb ES [16] had already mentioned the lack of money, the lack of time, the perfect knowledge of drugs and their use, the prescription to be renewed as factors influencing the practice of self-medication.

\section{Conclusions}

The image of self-medication has changed depending on both the changes in the health system and the evolution of the status of the patient considered today as an autonomous subject. This phenomenon occurs in the digital age, where medical information is made available to everyone on the internet and social networks.

This study has shown that self-medication through social networks is a reality among Senegalese women and can serve as a platform for prescribing traditional unlicensed drugs. This situation calls on all health actors because unsupervised self-medication can cause major individual and public health problems. Reinforcement of communication for health, through these networks should be operated to prevent the health risks that this practice could cause.

\section{Conflicts of Interest}

The authors declare no conflicts of interest regarding the publication of this paper.

\section{References}

[1] Fasseur, F. and Santiago, D.M. (2012) Comportements d'automédication et infirmières Recherche qualitative exploratoire. Pratiques Psychologiques, 18, 317-331. https://doi.org/10.1016/j.prps.2012.03.003

[2] World Health Organization (2000) Guidelines for the Regulatory Assessment of Medicinal Products for Use in Self-Medication. WHO, Geneva.

[3] Chiribagula, V.B., Mboni, H.M., Amuri, S.B., Kamulete, G.S., Byanga, J.K., Duez, P., et al. (2015) Prévalence et caractéristiques de l'automédication chez les étudiants de 18 à 35 ans résidant au Campus de la Kasapa de l'Université de Lubumbashi. Pan African Medical Journal, 21, Article 107. 
https://doi.org/10.11604/pamj.2015.21.107.5651

[4] Donkor, S., Tetteh-Quarcoo, P.B., Nartey, P. and Agyeman, O.I. (2012) Self-Medication Practices with Antibiotics among Tertiary Level Students in Accra. Ghana: A Cross-Sectional Study. International Journal of Environmental Research and Public Health, 9, 3519-3529. https://doi.org/10.3390/ijerph9103519

[5] Ndiaye, P., Tal-Dia, A., Diedhiou, A., Juergens-Behr, A. and Lemort, J.P. (2006) Self-Treatment of Fever in the Northern District of Dakar, Senegal. Médecine Tropicale: Revue du Corps de santé colonial, 66, 74-78.

[6] Kane, A.A. (1999) Automédication au Sénégal: Exemple de la ville de Dakar. Thèse Doc Pharm, Université Cheikh Anta Diop Faculté de Médecine Pharmacie et odontostomatologie, Dakar, M-42030.

[7] Desclaux, A. (2016) L'automédication comme pratique collective. Pratiques et fonctions dans la vente de compléments nutritionnels au Sénégal. ANR-AUTOMED.

[8] Sylla, A. (2014) L'automédication par les antibiotiques: Étude menée dans la commune de Guédiawaye. Thèse Doc Pharm, Université Cheikh Anta Diop Faculté de Médecine Pharmacie et odontologie, Dakar, thm_48728.

[9] Thiam, T. (2012) Pratique de l'automédication dans la commune de Grand Yoff: Enquête réalisée dans neuf officines de la commune. Thèse Doc Pharm, Université Cheikh Anta Diop Faculté de Médecine Pharmacie et odontologie, Dakar, THM-48289.

[10] Angouan'd, S.A.N. (1994) L'automédication au Cameroun: Exemple de la ville de Yaoundé. Thèse Doc Pharm, Université Cheikh Anta Diop Faculté de Médecine Pharmacie et odontostomatologie, Dakar, M-40272.

[11] Baxerres, C., Guienne, V., Houngnihin, R. and Marquis, C. (2015) L'automédication et ses déterminants. Les rencontres Nord/Sud. Cotonou.

[12] Agence Nationale de la Statistique et de la Démographie (Sénégal) (2014) Recensement géneral de la population. de l'habitat. De l'agriculture et de l'élevage (RHPHAE) 2013.

[13] Ministère de la santé et de l'action sociale du Sénégal (2018) Plan Stratégique Santé Digitale (PSSD) 2018-2023 du Sénégal.

[14] Agence Nationale de la Statistique et de la Démographie (Sénégal) (2018) Enquête démographique et de santé continue 2017.

[15] Vidzraku, S. (2018) Sénégal: Le nombre d'utilisateurs d'Internet a atteint 9.6 millions de personnes. La Tribune Afrique.

https://afrique.latribune.fr/africa-tech/2018-05-08/senegal-le-nombre-d-utilisateurs -d-internet-a-atteint-9-6-millions-de-personnes-777869.html

[16] Samb, E.S. (2011) Pratique de l'automédication dans la commune de Kaolack. Thèse Doc Pharm, Université Cheikh Anta Diop Faculté de Médecine Pharmacie et d'odontologie, Dakar, thm_47527.

[17] Kitengye, L.J. (2014) Analyse des facteurs déterminant l'automédication chez les personnes âgées cas du quartier Manenga. Commune de Ngaliema. Mémoire de licence en Sciences de la Santé. Université Pédagogique Nationale, Congo Kinshasa.

[18] Hariri, J. (2005) Allergie médicamenteuse: Etude rétrospective à propos de 458 cas colliges au centre national de pharmacovigilance de Rabat. Thèse Doc Pharm, Université Cheikh Anta Diop Faculté de Médecine Pharmacie et odontologie, Dakar.

[19] Queneau, P. and Decousus, H. (1985) Notion de thérapeutique générale. Manuel de thérapeutique médicale édition, MASSON, Paris, 42-43. 